\title{
Pedagogical Support of Self-Realization of the Person in Sports Activity
}

\author{
Vasiliy Vasil'yevich Nakhodkin, Svetlana Viktorovna Panina*, Lyudmila Vitalyevna Popova and \\ Aleksey Innokentyevich Golikov
}

\author{
M. K. Ammosov North-Eastern Federal University, Russia; monblan@yandex.ru
}

\begin{abstract}
This article is a study of questions of self-realization that are interpreted in the context of individual student's development, his self-determination and self-actualization as well as realization of his potential. Also, the authors support the opinion that self-realization is an integral multi-level phenomenon, comprising a plurality of interconnected components. The article reveals the components of pedagogical support of personal fulfillment in sports activity through the formation by the personality those settings that allow enriching self-motivation. The article examines the process of assistance in actions of self- cognition; the formation of the ability to look at himself "through the eyes of others"; seeing the strengths and weaknesses of his personality; the development of self-assessment skills, designing of ways for personal growth. The results of a pilot study of young sportsmen have been described, the levels of anxiety and emotional stability, the character of interpersonal relationships in a group and self-confidence have been show, the attitude of parents to the fact that their children have sports activity have been studied. The obtained data show a significant predominance of indicators of emotional stability and low levels of anxiety of adolescent athletes compare with the pupils, thereby a positive impact of sports activity on the considered personal characteristics have been proven. Designed by the authors "The Diary of athlete self-motivation" is presented as an effective tool for self-realization of the person of the young athlete.
\end{abstract}

Keywords: Pedagogical Support, Person, Self-Realization, Sports Activity, Young Sportsman

\section{Introduction}

In recent decades, the problem of self-realization is actively studied by Russian psychologists ${ }^{1-3}$, it allows to consider a person in the process of self-realization as an active one, understanding the meaning and realizing his abilities and opportunities, constantly improving himself in order to achieve certain results. Researchers consider self-realization as one of the factors of personal selfdetermination, along with self-knowledge, self-esteem, self-improvement, self-expression, self-regulation.

The foundation of self-realization are the results of constant self-identity, which is defined as a process of conscious and managed development in which the qualities and abilities of the person are formed and developed in the interest of the subject, purposeful improvement himself made by the person on the basis of the needs of self-development, that is, motion to the growth happens ${ }^{4}$.

The pedagogy the concept of "self-realization" has two substantive parts: personal features that ensure the implementation process himself as individual, it is based on the processes of self-knowledge; and conscious purposeful activity, the result of which is the selfrealization.

Studies of recent years are increasingly turning to the problem of self-realization, the representatives of humanistic psychology realize a personal fulfillment

\footnotetext{
* Author for correspondence
} 
center connected to self-knowledge, knowledge of his very self. The term "self-realization" is often synonymous with "self-fulfillment" and "self-actualization".

The researchers describe the problem of selfrealization as a human desire for the fullest identify and develop his capabilities and skills; as an internal active momentum to develop himself, something like true selfexpression. The concept of "self-realization" was used in works on psychology of personality by A. Adler. In his opinion, people first of all seek for supremacy that is the fundamental law of human life. The researcher does not give a psychological definition of self-identity being limited with philosophical approach. He also does not name the mechanisms of self-realization. However, Adler has always recognized that a person has self-conscience and he is able to plan his actions, manage them, and understand the importance of his actions for his own self-realization. According to A. Adler, the man himself creates his own personality. It has the creative "I", he aims and identify ways and achieve his goals. However, the aim is subjective, it exists "here and now", it may be unattainable fiction. Nevertheless, the goal is the real motivation. Through creative "I" the experience of the body get interpreted and comprehended, at the same time the experience in the implementation of life-style that is unique to the person is being sought ${ }^{6}$.

Self-cognition is seen as a mechanism of formation of the person, capable to do his self-determination and self-realization in the life, to design his own development. Pedagogical support of self-cognition includes such components as formation of understanding of importance of person's needs, enriching self-motivation; assistance in using activities of self-cognition; the formation of the ability to look at oneself "through the eyes of others"; to see the strengths and weaknesses of his personality; to develop skills of self-assessment, to design the ways for personal growth ${ }^{7}$.

The defining condition for self-realization is a process of socialization as the assimilation of social and cultural experience of society and building on this basis personal social experience.

If to turn to the questions of "pedagogical support", can be seen that this concept in Russian pedagogy is associated with the name O. S. Gazman, who considered them in terms of personal development and self-development. Developing the concept of pedagogical support researcher repelled from the fact that the child's development occurs most successfully when there is harmony of two essentially different processes - socialization and individualization. M. Montessori considers teaching support like the help the child to do something himself, not doing the work for him, the main thing here is to show the right way to do something to the child, and then he will do everything himself ${ }^{8}$. Analysis of the foreign studies of the questions of pedagogical support (R. Burns, K. Rogers, R. Smead and K. Fopel) allows to determine such conditions of realization of pedagogical support as openness, credibility, humanity, empathy, congruence, unconditional positive acceptance and understanding of student's individuality and his problems. Thus, the position of the teacher is seen facilitator-like, as promoting personal growth of the student, enabling the child to feel self-sufficient in achieving of his own success.

Experts present pedagogical support as a high-tech, psychological pedagogical activity aimed at identifying and developing the personal allowance for every child ${ }^{9}$.

So N. B. Krylova notes the fundamental difference between the support and traditional leadership in the fact that the teacher that interacts with a child on the basis of standards support sees the problem of the child not like "stress for himself" or like the fact of "compromising material" for future "organizational conclusions", but he sees the point of personal growth of the child, he creates with him a new educational situation in the area of his self-motivation, that makes the child the real subject of his own life and the identification, and through them the subject of his own education.

The norms of pedagogical support proposed by the researcher also are interesting. It is the creation and maintenance of conditions for the development of the child, taking into account the particular features of his self-development, individual needs and interests; readiness to provide operational assistance to the child and interaction with him; impulse the child to comprehend and solve his personal problems by himself; respect the child's right to choose and his manifestation of "self", including self-determination, self-organization, self-fulfillment and other; promoting independent actions of the child, thereby prompting a growing man to the understanding of vital, moral and educational values of choice and responsibility ${ }^{10}$.

Thus, pedagogical support is principally referred as the subject of the teacher's activity, at the same time the possibility of a young athlete become the subject of a situation in which he is interested. 


\section{Method}

In a pilot study a sport group was taken as an experimental object. It consists of 32 adolescents involved in sports for 2-3 years. For the reliability of the obtained information, the results have been compared with the results of physical training group (students of 8-11 years of school).

In order to determine the level of anxiety and emotional stability, the comparative testing of school students and athletes-wrestlers have been conducted. The level of self-esteem have been evaluated by the method of B. H. Spielberger, J. L. Hanin, the nature of interpersonal relations in the group have been studied according to Seashore's questionnaire of the index of group cohesion and method of A. I. Krupnov, sociometry, the study of attitudes of parents to their children's sports activities have been conducted by a using of the questionnaire of 48 parents of students of ulus gymnasium and children and youth sports school of the village Namtsy Namsky ulus of the Republic of Sakha (Yakutia).

Technique "Introspection of personality" of $\mathrm{O}$. N. Motkov can reveal strengths and weaknesses of the individual of young athletes, to activate the depth introspection of qualities (in depth version of those presentations). Such self-cognition is the first step of selfeducation of person.

At the beginning of doing sports $30 \%$ of students of the experimental group (10 of 32 students) showed conflictness and pointedly, 20\% (6 adolescents) have demonstrated a sense of insecurity, $20 \%$ (6 children) had a shyness and loneliness, i.e. development of negative qualities have been noted in 70\% (22 people). The main recommendations were like: to engage in sports or technical activities depends on student's interests, so it would help to transfer their energy in a positive way; to assist in the leadership, to encourage creative activity.

After 3-4 years of being involved in sports activities the same guys have showed a high level of moral and volitional qualities, it was revealed at $80.7 \%$ (26 adolescents); a sense of community and mutual also have showed by $87.5 \%$ ( 28 subjects) of adolescents of the experimental group, $65.6 \%$ (high level) of students have a sports team public initiative and creative activity. These data indicate the positive dynamics of the development of personal features.

The obtained data show a significant predominance of indicators of emotional stability and low levels of anxiety of adolescent-athletes compare with results of the students of the school, the positive effect of sports activities on the personal characteristics have been proved (Table 1).

Table 1. Levels of emotional stability and anxiety of adolescents - students of school and athletes, \%

\begin{tabular}{llcc}
\hline Group of adolescents & Level & $\begin{array}{c}\text { Emotional } \\
\text { stability }\end{array}$ & Anxiety \\
\hline Students of the school & High & 11,8 & 39,6 \\
& Average & 27,7 & 51,3 \\
& Low & 60,5 & 10,1 \\
Athletes & High & 46,7 & 3,2 \\
& Average & 45,5 & 43,8 \\
& Low & 7,8 & 53,0 \\
\hline
\end{tabular}

Whereas at the beginning of doing sports high anxiety was observed in 50\% (16 people), the level of self-esteem was $30 \%$ (10 people), in 2-3 years high anxiety was observed in $30 \%$ (it has reduced at $20 \%$ ). Currently the level of adequate self-esteem is $70 \%$, which means that the level of self-esteem has increased on $40 \%$, i.e. 22 students have believed into themselves, they have changed their attitude to themselves and began to respect themselves as personalities.

Table 2. Life plans of adolescents $\overline{\bar{\nu}}$

\begin{tabular}{|c|c|c|c|c|c|c|}
\hline \multirow[t]{2}{*}{ No. } & \multirow[t]{2}{*}{ Life plans } & \multirow[t]{2}{*}{$\begin{array}{l}\text { Number of votes } \\
\text { in schools K-2 }\end{array}$} & \multicolumn{2}{|c|}{$\begin{array}{l}\text { Number of votes in sports school } \\
(\mathrm{K}-1)\end{array}$} & \multicolumn{2}{|c|}{$\begin{array}{c}\text { Number of votes of gymnasium } \\
\text { students actively involved in sports }\end{array}$} \\
\hline & & & $\begin{array}{c}\text { Group of } \\
\text { initial training }\end{array}$ & $\begin{array}{l}\text { Group of third } \\
\text { year of studying }\end{array}$ & $\begin{array}{l}\text { Group of initial } \\
\text { training }\end{array}$ & $\begin{array}{l}\text { Group of third year } \\
\text { of studying (EG) }\end{array}$ \\
\hline 1 & To find a prestigious job & 31 & 1 & 0 & 17 & 26 \\
\hline 2 & To create a good family & 27 & 19 & 3 & 0 & 0 \\
\hline 3 & To have a lot of friends & 27 & 2 & 2 & 15 & 15 \\
\hline 4 & To study well & 18 & 5 & 0 & 27 & 30 \\
\hline 5 & To get a good education & 17 & 26 & 0 & 30 & 30 \\
\hline 6 & To become a personality & 13 & 9 & 5 & 9 & 28 \\
\hline 7 & To achieve material prosperity & 17 & 4 & 0 & 0 & 0 \\
\hline 8 & To gain respect & 6 & 1 & 0 & 3 & 16 \\
\hline 9 & To become famous & 3 & 1 & 0 & 2 & 0 \\
\hline
\end{tabular}


Table 4. Personal qualities of the teacher and trainer

\begin{tabular}{llll}
\hline Worldview qualities & Intellectual qualities & Psychotypological qualities & Extrovert qualities \\
\hline a desire to work with adoles- & possession of speech culture; & will; observation; self-control; self-reg- & altruism; goodwill; com- \\
$\begin{array}{l}\text { cents; love for the profession; } \\
\text { love for children; honesty; }\end{array}$ & readiness for self-improve- & ulation; restraint; steadiness; courage; & munication skills; charity; \\
$\begin{array}{l}\text { the presence of a professional } \\
\text { position;hardness }\end{array}$ & wit; good memory; erudition; & & justice; respect for the \\
sense of humor & & teenager; empathy \\
\hline
\end{tabular}

If we consider the motivation of doing sports, it is seen that $100 \%$ of students in the physical training group had the motive "to be healthy". It says about the narrow personal character of the motive, while $80.7 \%$ (26 students) of students of sports groups except the narrow personal motives also have wide social motives such as sense of duty and responsibility to the team and the school (for the gymnasium), 18.8\% (6 teenagers) have motives like the sportsmen do, it is the desire of self-improvement of personal results (for competitions).

\section{Results}

At the beginning of doing sports the survey results indicated the presence of disunity in the group (lack of sports discipline, mutual understanding, a sense of partnership, a sense of "we", etc.). After that the systematic work for the formation and development of interpersonal relationships in a small society has been done. In our opinion it is a children's sports team promotes creation of all the conditions and preconditions for overcoming their own negative psychological barriers by the students such as excessive shyness, feelings of inferiority, lack of confidence in their abilities, high anxiety, etc.

Re-examination of the social and psychological climate in the sports team according to the questionnaire index of group cohesion of Seashore has revealed a high score of the team attractiveness (28 points out of 35 ). Also, an adapted version of A. I. Krupnov's methodology has been used to assess the interpersonal relationships in the community and to determine the index of group cohesion of sports team. The obtained results showed good relationship in the team and a high index of group cohesion (18 points out of 20).

The results of questioning showed that parents choose sports activity for their children guided by the following motives: sport will become a career of their son (say $12 \%$ of parents); sport will provide a method to occupy the child's free time and form his character, moral and volitional qualities ( $48 \%$ of parents); sport will help to improve the health of the child ( $40 \%$ of parents). However, at the same time $88 \%$ of surveyed parents argue that the sport will not become a career of their child. A similar picture can be seen in the responses of adolescents. By the end of school, after doing sport activities for 3-4 years, most teenagers do not connect their lives and work with professional sport (70\%). At the same time they see the value of sport in its ability to prepare the adolescent for the life, to a particular profession, to improve their health, and most importantly to form a adolescent as a person.

Thus, the results of the study showed that active occupation of teenagers by sports activity fundamentally changes the nature of their fears and concerns. Adolescents believe in their abilities and capabilities, sports activity give them confidence. Adolescents involved in sports tied for first place the socially important and valuable personal wishes and dreams such as to get a good education (30 votes), to find himself as a person (11 votes). Human qualities most valued by teenagers remained unchanged in both groups of adolescents.

We consider these conclusions accurate, since no special selection of adolescents was conducted. The difference between the groups of surveyed adolescents consisted only in their relation to the sports activity. Therefore, it is this activity provides self-improvement of the person and its self-realization. If at the initial stage of doing sport the adolescents have prevailing values related to the expression of the physical "I", to the functional content of lessons, to with self-actualization, than at the final stage of learning the value of self-development of personality came to the fore.

\section{Discussion}

Researches of many specialists note that the concept of self-realization originates from works of Nietzsche and Jung, in different variants it is also showed at works of K. Horney, E. Fromm, K. Goldsheyn, A. Maslow and 
other authors who have tried to create all-encompassing theories of finite life goals. As the researchers note, the idea of the human implementation of potentialities inherent in him in one way or another can be found in many philosophical systems beginning from Aristotle. It is noted that the conceptual design on a psychological level which formed the basis of modern theories of selfactualization, firstly has been mentioned in the works of eminent physiologist and psychologist K. Goldstein. On the one hand the researcher opposed the principle of homeostasis which was dominant in biology and psychology of that time and the stress reduction as the main driving force of behavior, and on the other hand, he was against elementaristic approach to holistic living organism.3 At the same time, under certain conditions, the tendency to actualize any of these potencies can dominate that much that the body will mostly be moved by one of them. Self-realization in sports is the realization of his potential in achieving the practical (sports) results on the basis of improvement and expressing himself in a meaningful activity.

The main goal of activities in the sphere of physical culture is physical and mental perfection, that is, achieving harmony in the process of personality development through systematic training and the special exercises. Efficiency and systematic of lessons manifests itself in a certain level of development of physical characteristics and motor skills.

The researchers determine the benefits of sports activity as a value-relevant. It forms skills of hard work, high physical activity prepare the adolescent to overcome difficulties, thus contributing to the development of moral and volitional qualities; it develops personal qualities required in any other activity, including learning and cognitive process: the ability to focus on achieving the goal; concentration and stability of attention; a motional intellect, etc. The adolescent gets an opportunity to coordinate his actions, there is not only responsible for his own actions appears but for the actions of the collective, the team ${ }^{11}$.

The problem of the study of personal fulfillment in sports activity has been considered on the basis of the provisions of the system approach, according to which the self-realization of the athlete is regarded as a holistic multi-level phenomenon comprising a plurality of interconnected components. The personal and the activity approach enabled to characterize the psychological support as an important driving force of personality development and formation of self-realization of the athlete, as well as to study its expression in the dynamics and the relationship with the forms and conditions.

O. S. Staver allocates the structure of personal fulfillment in physical culture and sport which includes the following components: motivational-value (values of life, sports and physical training needs and motives, the possibility of sports activity, the achievement of sports results, interest in creative sports activity, capacity for reflection); emotional and volitional (interaction with the outside world, the joint solution of conflicts, ability for autonomous behavior, commitment, etc.); reflexive and activity (responsibility for the acts and actions, social relationships, systematic of sports activities, independence and originality of sports activity forms, etc) ${ }^{12}$.

V. E. Bushmanova includes the following components into the structure of self-realization of the young athlete: semantic, motivational, emotional, psycho-physiological, reflective ${ }^{13}$.

Exactly the process of self-realization in sports activity may have several paths of self-motivation: body and correction, recreational and correction, motional and conditioning, sports and recreational, artistic and aesthetic, professional and crafting, sport and volunteer, etc.

During the pilot study, we have also been interested to learn about the life plans of adolescents, to understand how participation in sports activities can influence the process of self-realization.

The survey results indicate that active sports activity radically changes the nature of the fears and concerns of adolescents. Adolescents are not afraid of loneliness, violence, death, disease, etc., it is the sports activity that give them confidence in their abilities and capabilities. So, the involved in sport adolescents put in the first place the socially important and valuable personal wishes and dreams like "to get a good education" (30 votes), "to find myself as a personality" (11 votes). Human qualities most valued for teenagers are remained unchanged in both groups of adolescents. We believe that presented conclusions are reliable because there no special selection of adolescents was conducted. The difference between the surveyed groups is consisted only in their relation to the sports activities. Therefore it is sports activity ensures the formation of socially significant qualities of the person.

We also consider that the personal qualities of the teacher are substantially significant moment in the questions of pedagogical support. This is due to the fact 
that the example of the teacher and trainer is often decisive for the adolescent. As the results of the pilot study showed, the presence of such qualities as the desire to work with young people; honesty; the presence of a professional position; possession of speech culture; readiness for selfimprovement; calmness; sense of humor; will; self-control; self-regulation; tolerance; goodwill; communication skills; organizational skills; justice; empathy, and others are a characteristic portrait of a teacher.

It is student-centered approach ensures consideration of individual psychological and age characteristics of adolescents. The initial component of a process of organization of sports activity of teenagers is to define the conditions for the organization of pedagogical support of personal fulfillment: providing positive motivation to the collective sports activity and a real self-assessment by adolescents their own capabilities; education of value concepts of adolescents about collective sports activities; improved knowledge about the sphere of physical culture and sports.

We consider one of the effective tools for selfimprovement The Diary of athlete self-motivation", the young athlete captures the aims and objectives of sports self-improvement in it, such as long-term goal (for the next 1-2 years), a year-long (overall and by periods of training) regular and the immediate tasks. Then, the teenager has set specific goals for himself and describes the ways and means of achieving each of them. At the same time young athlete uses individual techniques for self-stimulation of willpower. These include: mobilizing techniques (self-persuasion, appeal to the sense of duty, self-approval, self-motivation, self-love game, self-order, self-prohibiting and others) and will organizing methods associated with switching attention and others.

The structure of the "The Diary of athlete selfmotivation" 11 includes personal data of the athlete, the description of the goals and objectives in the training year (in the form of essays or plan), self-assessments and characteristics of the results of the educational, training, competition and other activities.

It consists of sections "The self-tasks for a week", "Selfesteem of the achieving of the tasks for the day and for the week" with a description of the difficulties in the process of activity in specific dates, "Analysis of the difficulties for the week", it also includes a Portfolio of personal achievement of the athlete where the athlete clearly describes his goals and plans of educational, training and other activities in the educational and training year, and he evaluates the characterization of the results in the form of essays. For example, adolescents fill the following plan (Table 5)

The structure of the characteristics of individual achievements consists of the achievements in the field of educational activity, sports and creative activities, as well as the characteristics of the development of moral and volitional efforts of the student and his attitudes to work, the development of independence and responsibility of the student-athlete, the focus on cooperation with members of the children's sports team. We also provide brief methodical recommendations for the teacher and trainer working with young athletes that will help to fill "The Diary of athlete self-motivation".

иable 5. Personal educational and training plan of the student

\begin{tabular}{lll}
\hline No. & Educational and training cycles & Quantity \\
\hline 1 & Required general physical training \\
2 & Required special physical training \\
3 & The main \\
4 & Competitive \\
5 & Precompetitive \\
6 & Restorative \\
7 & Development of characteristics of speed \\
8 & and strength \\
9 & Development of endurance \\
10 & Developing of flexibility and agility \\
& $\begin{array}{l}\text { actions } \\
11\end{array}$ & The moral and psychological preparation \\
\hline
\end{tabular}

\section{Conclusion}

The presence of the important for the person rules plays an important role in self-improvement: for education of purposefulness (if you set a goal you should go for it firmly, the implementation of the plan is the basis of success, to summer up the results when a day is over), for perseverance and persistence (do not that things that you like, but those things that should be done; the reason for obstacles to exist is that you could overcome them), for determination (first you need to understand, then you need to make a decision; if you decided to do something, you should do it), endurance and self-control (learn how to control yourself; do everything only in the best way), independence and initiative (do not rely only 
on the coach, even if he is the best; do not expect when someone will give you an advise and a task, act by your own initiative; be the strictest judge for yourself).

Search for the optimal level of task difficulty bringing moral satisfaction to the young athlete, it also affects the moral and volitional self-improvement, as well as systematic and gradual increase of requirements, control, clarity and organization of training activities.

The concept of self-realization in the sports activities requires new comprehension from the perspective of contemporary social consciousness with taking into account the conditions of post-industrial cultural epoch ${ }^{12}$. The studies of this help to the person to push the horizons of self-conscience.

\section{References}

1. Klochko VE. Systematic ontological pedagogy: psychological and psycho-physiological rationale. Vestnik Novosibirskogo gosudarstvennogo pedagogicheskogo universiteta. 2014; 6(22). Available from: http://cyberleninka.ru/article/n/sistemnaya-ontopedagogika-psihologicheskoe-i-psihofiziologicheskoe-obosnovanie.

2. Horskaya GB. Psychological effects of the early professionalization of person. "Chelovek. Soobshchestvo. Upravlenie». 2008; 3:106-13.

3. Leontiev D. Personal meaning a challenge for psychology. The Journal of Positive Psychology. 2013; 8 (6):459-70.

4. Zhurakovskaya VM. Technologies of student's self-realization. Mir nauki, kultury, obrazovaniya. 2009; 1.
5. Bazaeva FU. An analysis of the phenomenon of self-realization in the foreign humanistic psychology. Srednee professional'noe obrazovanie. 2012; 3.

6. Adler A. Understanding Human Nature. Series: Psychological Science. Moscow: Publisher Akademicheskiy proekt. 2015; 4:248.

7. Ignatovich VK. Pedagogical conditions of self-determination of the adolescent in the course of additional education. Abstract of the candidate of pedagogical sciences. Sochi. $2001 ; 24$.

8. Kurnikov NV. The essence of the concept of pedagogical support in education. Mir nauki, kultury, obrazovaniya. 2012; 5(36):74-74.

9. Leonova EV. Pedagogical support of development of creative thinking of children in additional education establishments. Author's abstract on competition of the candidate of pedagogical sciences. Moscow; 2002.

10. Krylova NB. Pedagogical support and educational communication. The socio and pedagogical problems of valuable self-determination of the person. Materials of All-Russian scientific-practical conference. Ulyanovsk: Ulgpu; 2005. p. 193-201.

11. Nakhodkin VV. Moral and volitional development of adolescents in sports activity: monograph. Moscow: MGOU. $2007 ; 110$.

12. Staver OS. Self-realization in sphere of physical culture and sports. Bulletin of P.P. Ershov IGPI. 2012; 1(5):10-112. Available from: https://e.mail.ru/attachment/14426507930000000953/0;1

13. Bushmanova VE. Self-realization of the adolescent in a playful sports. Fizicheskaya kultura: vospitanie, obrazovanie, trenirovka. 2012; 3:77-85. 